\title{
Improving EFL Graduate Students' Proficiency in Writing through an Online Automated Essay Assessing System
}

\author{
$\mathrm{Ke} \mathrm{Ma}^{1}$ \\ ${ }^{1}$ Shaanxi Normal University, China \\ Correspondence: Ke Ma, School of Foreign Languages, Shaanxi Normal University, Xi'an, 710062, China. \\ E-mail: mkpolo@snnu.edu.cn
}

Received: April 3, 2013 Accepted: April 23, 2013 Online Published: June 3, 2013

doi:10.5539/elt.v6n7p158 URL: http://dx.doi.org/10.5539/elt.v6n7p158

The research is financed by the Key Teaching Reform Research Project of Shaanxi Normal University (ZDXMZYJS045).

\begin{abstract}
This study investigates the effects of using an online Automated Essay Assessing (AEA) system on EFL graduate students' writing. Eighty four EFL graduate students divided into the treatment group and the control group participated in this study. The treatment group was asked to use an AEA system to assist their essay writing. Both groups were pretested before the treatment. After the sixteen-week treatment period, the writing posttest was given to both groups to measure their progress in their writing. The results indicate that, although both groups have no significant difference in the pretest, the difference between their mean scores on the posttest is statistically significant. The mean score of the treatment group is higher than that of the control group, and students' use frequency of the AEA system is closely related to their writing improvement. Therefore, it is concluded that, students' using the AEA system contributes significantly to their writing improvement. Thus a linear regression is modeled to predict the weight of the AEA system use frequency to proficiency improvement in writing. Finally, students' perceptions based on their learning journals and interviews show the changes in the process of writing.
\end{abstract}

Keywords: online Automated Essay Assessing system, proficiency in writing, EFL graduate students

\section{Introduction}

Educational Assessment should have a clear benefit in direct services to learners since its primary function is to foster learning. It is widely regarded as contributing to learning if properly handled and administered. With computer science and information technology booming speedily, electronic assessment (E-assessment) is increasingly maturing, either as commercial products or in academic research field. Automated Essay Scoring (AES) system has been widely recognized since it was first constructed in 1966. E-rater developed by American Educational Testing Service, for instance, has already been employed in the large-scaled language tests, such as GMAT. (Wang \& Wen, 2010)

At the same time, information technology is used to make education so effective that English learning is not confined to location and timing, but focuses more on individualized and autonomous learning. On the other hand, classes in China are usually so large-sized that it's really difficult for teachers to give feedbacks to students timely.

Therefore, it's beneficial to use AES system to score essays for the sake of saving time, but it only serves as summative assessment of learning while what really improves learning is actually formative assessment for learning. So does Automated Essay Assessment (AEA) effectively help learners with their writing? This is why the paper tries to explore the effects of AEA on EFL learners' proficiency and behaviours in writing.

\subsection{AES and AEA}

E-assessment is becoming increasingly widely used due to its many advantages over traditional paper-based assessment by markers. The advantages mainly comprise instant feedback to students, lower long-term costs, ensured impartiality, improved reliability, greater storage efficiency, greater flexibility with respect to location 
and timing, enhanced question styles which incorporate interactivity and multimedia.

E-assessment applied to writing is AES and AEA. According to researchers (Rudner \& Liang, 2002; Dikli, 2006), AES is defined as the computer technology that evaluates and scores the written prose so as to overcome time, cost, reliability, and generalizability issues in writing assessment. In order to distinguish their specific functions, however, the author uses different terms, namely AES and AEA, to refer to assessment of learning (score only) and assessment for learning (score + feedback) respectively.

The AES and AEA systems have gone through three stages: (1) spelling checker; (2) grammar checker; (3) usage checker. The landmark AES and AEA systems include Project Essay Grade (PEG), Writer's Workbench, Bayesian Essay Test Scoring System, Pacific Metrics, Automated Student Assessment Prize, Intelligent Essay Assessor (IEA), E-rater and etc. (Wang \& Wen, 2010; Valenti, Neri \& Cucchiarelli, 2003).

\subsection{Online AEA System (http://www.pigai.org/)}

The online AEA system (http://www.pigai.org/) falls into the category of the third stage. It is based on the large-scale corpus to compare the uploaded essays. It checks whether the collocation and the chunks are authentic to spot out the typical Chinglish which is ungrammatical or nonsensical English influenced by the Chinese language in Chinese contexts. It takes advantages of cloud computing, which timely responds to student's essay uploaded by scoring, reviewing the whole essay as well as analyzing each sentence automatically. It's characterized by automatically correcting simple mistakes, scoring immediately, plagiarism detecting, and progress reports. It possesses the following functions.

(1) Grading: the students' essays are graded immediately in the system after they are uploaded so that students can know their scores timely. Below the score are four separate measuring indices for the essay, including vocabulary, sentence, text structure, and content relevancy.

(2) Commenting: there are the comments on the whole essay under the separate measuring indices.

(3) Pointing out mistakes: those mistakes range from spelling mistakes, to word usage mistakes, even to collocating mistakes.

(4) Tips for learning: the word discrimination is offered as tips for learning.

(5) Advice for correcting: the students are given advice to polish their essays in the system.

(6) Process record: the students' correcting processes are recorded not only in table of use frequency and score recorded with time (Table 1) but in figure of scoring track. (Figure 1)

Table 1. Use frequency and score recorded with time

\begin{tabular}{lll}
\hline 版本 version & 时间 time & 成绩 score \\
1 & $2012-06-06$ 23:07:36 & 84 \\
2 & $2012-06-09$ 16:51:21 & 85 \\
3 & $2012-06-09$ 17:34:35 & 85.5 \\
4 & $2012-06-09$ 17:45:58 & 86.5 \\
5 & $2012-06-0918: 02: 39$ & 87 \\
6 & $2012-06-1123: 20: 09$ & 88 \\
7 & $2012-06-1220: 31: 27$ & 88.5 \\
8 & $2012-06-1220: 44: 04$ & 88.5 \\
9 & $2012-06-1221: 04: 55$ & 89 \\
10 & $2012-06-1222: 47: 30$ & 90 \\
11 & $2012-06-1223: 06: 01$ & 91 \\
\hline
\end{tabular}

Table 1 shows the time the student uploads his essay, and score of each revised version of the same essay. 


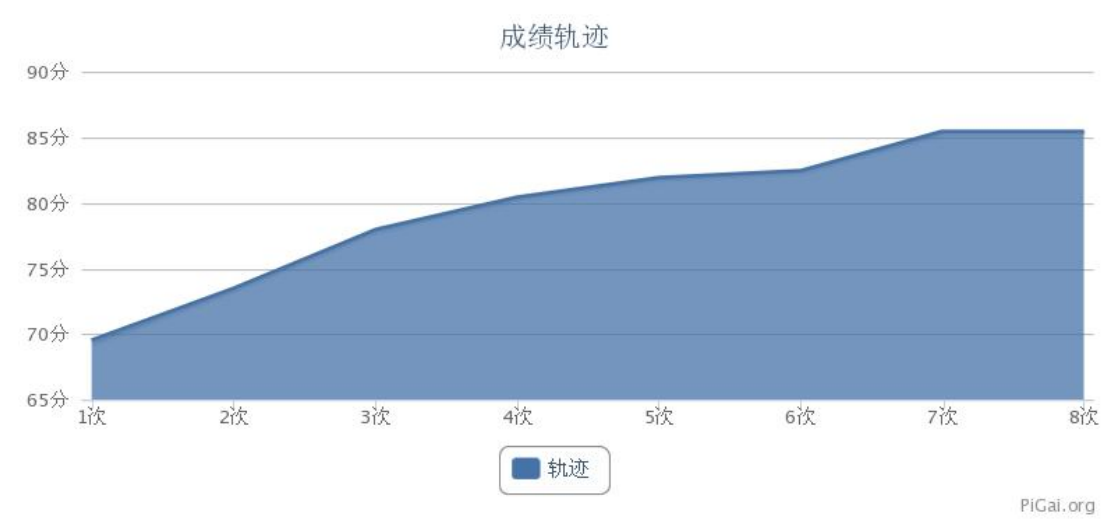

Figure 1. Scoring Track

Figure 1 keeps track of how the score is improved from 69.5 to 80.5 in the 8 versions.

\subsection{Literature Review}

In the studies on language testing, essay scoring methods are divided into holistic scoring and analytical scoring. According to Weigle (2002), although the latter is time-consuming, it is essential to ensure the scoring reliability, compared with the former. The AEA system used in the research adopts the analytical scoring.

The research in AES and AEA are mainly conducted in the aspects of technology and theory. Some researchers (Rudner \& Liang, 2002) focus on the mathematical modeling techniques and statistical techniques, such as linear regression, and Bayesian inference. Kakkonen, Myller \& Sutinen (2008) compare the dimension reduction methods for automated essay grading. Some others concentrate on comparative studies of different AES or AEA systems. Among them, Valenti, Neri \& Cucchiarelli (2003) present an overview of the current automated essay assessing systems, such as Intelligent Essay Assessor, Project Essay Grade, Educational Testing service, and etc., by describing and comparing their general structure and the performance. Liang and Wen (2007) evaluate and compare three representative AES systems against the major assessment criteria in essay scoring in the field of language testing.

In the field of EFL teaching and learning, Tang \& Wu (2011) review the studies of AEA in classroom assessment, and Sun (2012), Tang \& Wu (2012) study the practice of AEA system in undergraduate English teaching. But there is no research linking the AEA system with autonomy and proficiency in writing at the graduate student level.

\subsection{Research Questions}

The research is derived from learner autonomy which is theoretically based on cognitivism and humanism. Developing learner autonomy plays an important role in the theory and practice of language teaching. In the research on general education, the claim is often expressed strongly that autonomy is linked with more effective learning. According to the researchers on applied linguistics (Holec, 1985; Little, 1991), autonomy is also seen as a capacity for active, independent learning. In addition, autonomy can be seen as an attitude towards learning for which the learner is prepared (Dickinson, 1995). Cognitive learning mainly deals with the cognitive processes involved in learning, combining what is to be learned with what has been learned, which is what Bruner's (1966) discovery learning model suggests. Humanistic learning, on the other hand, mainly focuses on individual needs, values, motivations, and so on. (Guey, Cheng, \& Shibata, 2010)

It is true that AES and AEA systems can enhance efficiency and fairness when introduced into large-scale operational use. But can they really offer informative feedback to effectively help improve learners' writing. Therefore, it's of significance to conduct an empirical research in the effects of AEA system on learners' writing from the learner-centered perspective. Herein are the research questions:

(1) Is the use of AEA system effective in improving EFL graduate students' writing?

(2) To what extent does the use of AEA system contribute to improving EFL graduate students' proficiency in writing?

(3) Can EFL graduate students autonomy in writing be enhanced through the use AEA system? 


\section{Method}

\subsection{Participants}

Eighty four participants were EFL students from two parallel postgraduate English classes taught by the author in China. The two classes were randomly assigned to be treatment group and control group. The participants were all from of School of Life Science and their ages ranged from 22 to 27.

\subsection{Instruments}

The research adopted both quantitative and qualitative methods. Wherein, quantitative method encompasses the comparison between two classes' pretest and posttest scores; and the qualitative method was mainly based on students' interviews and learning journals. The pretest and posttest were marked and reviewed by the same group of teachers teaching the same module.

\subsection{Procedures}

The experiment was conducted for sixteen weeks from February, $27^{\text {th }}$ to June, $16^{\text {th }}, 2012$. Both classes were assigned 8 essays ( 1 every two weeks) to write during the treatment period. Before the experiment, all participants were tested in their writing by a group of teachers in the same module. In the experiment, the author introduced the online AEA system (http://www.pigai.org/) to the treatment group and assigned the essay task online for each of which, thus, there was the specific essay number accordingly. Then they registered their own accounts free of charge and searched for the essay task assigned according to its specific number, and were asked to have their essays assessed through this online AEA system before they handed in their essays to their teacher. They could have their essays scored and get the feedback the moment they uploaded their writing to the system, so if they were not satisfied with the results, they might revise their essays to their content. The treatment group was, at the same time, asked to keep a journal of their experience with the system. After that, they handed in their revised essays every two weeks, and the author interviewed some of them. Controversially, the control group was only assigned with the essay tasks without any other particular requirements. All the essays from both groups were done autonomously after class. After the experiment, all the participants were tested again by the same group of teachers teaching the same module.

The starting point for investigating these research questions is to assume the null hypotheses.

Hn1: There's no significant difference between the treatment group and the control group in pretest.

Hn2: There's no significant difference between the treatment group and the control group in posttest.

Hn3: There's no significant difference between the pretest and the posttest in the treatment group.

The treatment group was asked to keep their learning journals while using the AEA system, and interviewed after the treatment.

\subsection{Data Collection}

The research was designed as the flow chat showed in figure 2, in which treatment group was treated with the AEA system, and the two groups were both tested before and after the experiment.

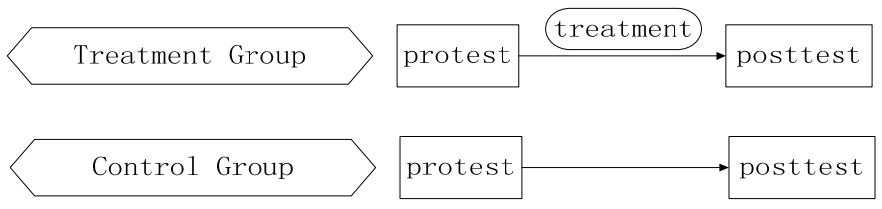

Figure 2. Flow Chat of Experiment

Data were collected from two tests, frequency of using the online AEA system which was recorded in students' account. Variables input into SPSS 17.0 for processing include pretest score, posttest score, frequency, and score improved. Some data of improved scores needed to be normalized before input due to minus. Efficacy Coefficient Method was adopted to normalize the improved scores to confine them between 0 and 1 . It was expressed in the following formula (1).

$$
X^{\prime}=\frac{X-X \min }{X \operatorname{man}-X \min }
$$

T-test was employed to test whether there is significant difference between the treatment group and the control group in pretest scores, whether there is significant difference between the two groups in posttest scores, and 
whether there is significant difference between the pretest and posttest scores in the treatment group. Pearson correlation coefficient $r$ was calculated to explore whether students' scores improved are related to their frequency of using the system. Then to what extent are they correlated to each other if there is a correlation? Is it possible to establish a mathematical model to explain the factors which may influence the scores improved?

Students' learning journals and interviews were also sorted out to analyze students' perceptions on the AEA system.

\section{Results and Discussion}

\subsection{Relation between the Treatment Group and the Control Group in Pretest}

Before the experiment, all the participants were pretested to see whether there is significant difference between the treatment group and the control group in pretest.

Table 2. Paired Samples Statistics of Pretests

\begin{tabular}{llllll}
\hline & & Mean & $\mathrm{N}$ & Std. Deviation & Std. Error Mean \\
\hline Pair 1 & treatment pretest & 60.33 & 42 & 8.734 & 1.348 \\
\cline { 2 - 6 } & control pretest & 60.95 & 42 & 8.560 & 1.321 \\
\hline
\end{tabular}

The mean pretest scores of the treatment group and the control group are 60.33 and 60.95 , respectively (Table 2).

Table 3. Paired Samples Test in Pretests

\begin{tabular}{|c|c|c|c|c|c|}
\hline & \multicolumn{4}{|c|}{ Paired Differences } & \multirow{3}{*}{$\begin{array}{l}\text { Sig. } \\
\text { df (2-tailed) }\end{array}$} \\
\hline & \multirow{2}{*}{$\begin{array}{l}\text { Std. } \\
\text { Mean Deviation }\end{array}$} & \multirow{2}{*}{$\begin{array}{l}\text { Std. Error } \\
\text { Mean }\end{array}$} & \multicolumn{2}{|c|}{$\begin{array}{l}95 \% \text { Confidence Interval of } \\
\text { the Difference }\end{array}$} & \\
\hline & & & Lower & Upper & \\
\hline $\begin{array}{l}\text { Pair } 1 \text { treatment pretest } \\
\text { control pretest }\end{array}$ & - -.619 13.713 & 2.116 & -4.892 & 3.654 & -.29341 .771 \\
\hline
\end{tabular}

Paired samples test of the treatment group and the control group in the pretest is shown in Table 3 . Because $\mathrm{t}=-0.293, \mathrm{p}=0.771>0.05, \mathrm{Hn} 1$ is accepted, which indicates that there is no significant difference between the treatment group and the control group in pretests even though the mean score of the control group is slightly higher than that of the treatment group. So all the participants are of the homogeneity and the two groups are well fit into the statistical sampling to serve as the rational samples.

\subsection{Relation between the Treatment Group and the Control Group in Posttest}

After the experiment, all the participants were tested again to investigate the relation between the treatment group and the control group in posttest.

Table 4. Paired Samples Statistics of Posttest

\begin{tabular}{llllll}
\hline & & Mean & N & Std. Deviation & Std. Error Mean \\
\hline Pair 1 & treatment posttest & 64.57 & 42 & 7.157 & 1.104 \\
\cline { 2 - 6 } & control posttest & 61.10 & 42 & 9.852 & 1.520 \\
\hline
\end{tabular}

The mean posttest scores of the treatment group and the control group are 64.57 and 61.10, respectively (Table 4). If $\mathrm{Hn} 2$ can be rejected, then their difference is statistically significant. 
Table 5. Paired Samples Test in Posttest

\begin{tabular}{|c|c|c|c|c|c|c|c|}
\hline & \multicolumn{5}{|c|}{ Paired Differences } & \multirow[b]{3}{*}{$\mathrm{df}$} & \multirow{3}{*}{$\begin{array}{l}\text { Sig. } \\
\text { (2-tailed) }\end{array}$} \\
\hline & \multirow[b]{2}{*}{ Mean } & \multirow{2}{*}{$\begin{array}{l}\text { Std. } \\
\text { Deviation }\end{array}$} & \multirow{2}{*}{$\begin{array}{l}\text { Std. Error } \\
\text { Mean }\end{array}$} & \multicolumn{2}{|c|}{$\begin{array}{l}95 \% \text { Confidence Interval } \\
\text { of the Difference }\end{array}$} & & \\
\hline & & & & Lower & Upper & & \\
\hline $\begin{array}{l}\text { Pair } 1 \text { treatment posttest } \\
\text { control posttest }\end{array}$ & -3.476 & 11.158 & 1.722 & .000 & 6.953 & 2.01941 & .049 \\
\hline
\end{tabular}

Table 5 shows the paired samples test of the treatment group and the control group in posttest. Because when $\mathrm{t}=2.019, \mathrm{p}=0.049<0.05, \mathrm{Hn} 2$ is not accepted, which indicates that there is significant difference between the treatment group and the control group in posttests. It proves that the posttest score of the treatment group is significantly higher that of their control counterparts.

\subsection{Relation between the Pretest and the Posttest in the Treatment Group}

Then the relation between the pretest and the posttest in the treatment group is tested to examine whether the posttest score is statistically significantly higher than the pretest score in the treatment group.

Table 6. Paired Samples Statistics of the Pretest and the Posttest in the Treatment Group

\begin{tabular}{llllll}
\hline & & Mean & $\mathrm{N}$ & Std. Deviation & Std. Error Mean \\
\hline Pair 1 & treatment pretest & 60.33 & 42 & 8.734 & 1.348 \\
\cline { 2 - 5 } & treatment posttest & 64.57 & 42 & 7.157 & 1.104 \\
\hline
\end{tabular}

In the treatment group, the mean scores of the pretest and the posttest are 60.33 and 64.57, respectively (Table 6). If Hn3 is not accepted, then there's significant difference between the pretest and the posttest in the treatment group.

Table 7. Paired Samples Test in Pretest and the Posttest in the Treatment Group

\begin{tabular}{|c|c|c|c|c|c|c|}
\hline & \multicolumn{5}{|c|}{ Paired Differences } & \multirow{3}{*}{$\begin{array}{l}\text { Sig. } \\
\text { df }(2 \text {-tailed) }\end{array}$} \\
\hline & \multirow[b]{2}{*}{ Mean } & \multirow{2}{*}{$\begin{array}{l}\text { Std. } \\
\text { Deviation }\end{array}$} & \multirow{2}{*}{$\begin{array}{l}\text { Std. Error } \\
\text { Mean }\end{array}$} & \multicolumn{2}{|c|}{$\begin{array}{l}\text { 95\% Confidence Interval of } \\
\text { the Difference }\end{array}$} & \\
\hline & & & & Lower & Upper & \\
\hline $\begin{array}{c}\text { Pair } 1 \text { treatment pretest } \\
\text { treatment posttest }\end{array}$ & --4.238 & 6.277 & .969 & -6.194 & -2.282 & -4.37541 .000 \\
\hline
\end{tabular}

And when $\mathrm{t}=-4.375, \mathrm{p}=0.000<0.001$ (Table 7), $\mathrm{Hn} 2$ is rejected, so the posttest score is statistically significantly higher than the pretest score in the treatment group.

Table 8. Paired Samples Correlations of Pretest and the Posttest in the Treatment Group

\begin{tabular}{lllll}
\hline & & $\mathrm{N}$ & Correlation & Sig. \\
\hline Pair 1 & treatment pretest \& treatment posttest & 42 & .705 & .000 \\
\hline
\end{tabular}

At the same time, when $\mathrm{r}=0.705, \mathrm{p}=0.000<0.001$ (Table 8 ), pretest and posttest are closely related. It can be concluded from table 6 that students in the treatment group improved their writing scores by 4.24 on average, by using the online AEA system. Therefore, the online AEA system contributes a lot to improving students writing. 


\subsection{Relation between Students' Scores Improved and Use Frequency of AEA System}

Since some data of improved scores are minus, they are normalized between 0 and 1 through Efficacy Coefficient Method (Formula 1).

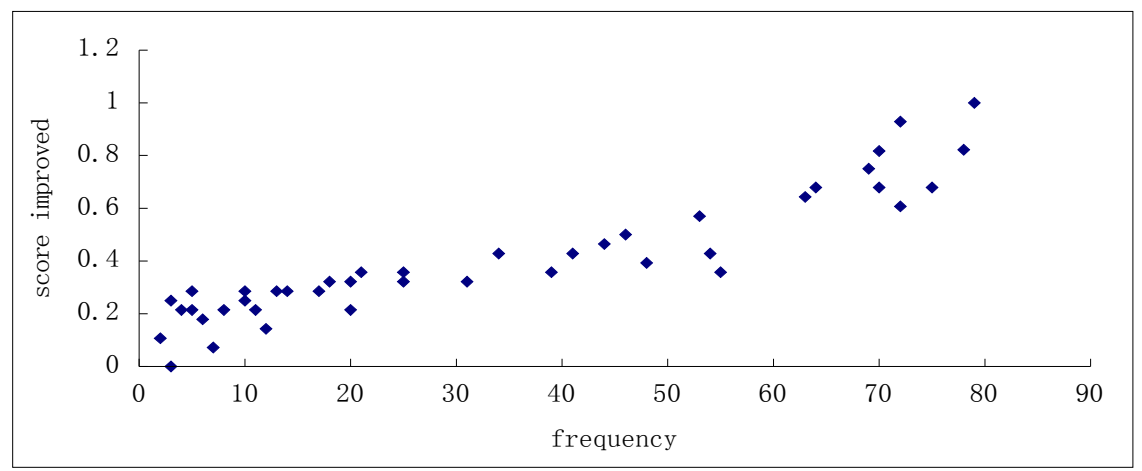

Figure 3. Scatter Diagram of Score Improved and Frequency

Then the scatter diagram is drawn to detect the relation between the frequency of students' using the online AEA system and how much they improve their writing in simple straightforward way (Figure 3). It's obvious that hey are related to some extent in a linear way.

Table 9. Correlations between Students' Scores Improved and Use Frequency of AEA System

\begin{tabular}{llll}
\hline \multirow{2}{*}{ score improved } & Pearson Correlation & score improved & frequency \\
\cline { 2 - 4 } & Sig. (2-tailed) & \multicolumn{1}{c}{. } & $.094^{* *}$ \\
\cline { 2 - 4 } & $\mathrm{N}$ & 42 & .000 \\
\hline \multirow{2}{*}{ frequency } & Pearson Correlation & $.894^{* *}$ & 1 \\
\cline { 2 - 4 } & Sig. (2-tailed) & .000 & \\
\cline { 2 - 4 } & $\mathrm{N}$ & 42 & 42 \\
\hline
\end{tabular}

**. Correlation is significant at the 0.01 level (2-tailed).

Then Pearson's Correlation Coefficient is tested to describe the specific degree of their relation. When $\mathrm{r}=0.894$, $\mathrm{p}=0.000$, it's significant that students' writing improvement is highly related to their use frequency of AEA system.

\subsection{Modeling Students' Writing Improvement}

Since students' score improved and the frequency of AEA system use are significantly highly correlated $(r=0.894, p=0.000$, table 9), and so are pretest scores and posttest scores ( $r=0.705, p=0.000$, table 8$)$, it's possible to model a linear regression by SPSS 17.0. The method selected is stepwise.

Table 10. Model Summary

\begin{tabular}{lcccr}
\hline Model & R & R Square & Adjusted R Square & \multicolumn{2}{l}{ Std. Error of the Estimate } \\
\hline 1 & $.705^{\mathrm{a}}$ & .497 & .484 & 5.141 \\
\hline 2 & $.927^{\mathrm{b}}$ & .859 & .851 & 2.760 \\
\hline a. Predictors: (Constant), treatment pretest & & \\
\hline b. Predictors: (Constant), treatment pretest, frequency & & \\
\hline
\end{tabular}


In table 10, two variables enter the model stepwise to be predictors, namely, pretest scores and use frequency. With the stepwise of the two variables, the adjusted $r$ square increases accordingly from 0.484 to 0.851 . They may account for $85.1 \%$ of the change.

Table 11. ANOVA ${ }^{\mathrm{c}}$

\begin{tabular}{llrrrrr}
\hline \multicolumn{1}{l}{ Model } & Sum of Squares & df & Mean Square & F & \multicolumn{1}{l}{ Sig. } \\
\hline 2 & Regression & 1803.192 & 2 & 901.596 & 118.354 & $.000^{\mathrm{b}}$ \\
\cline { 2 - 8 } & Residual & 297.094 & 39 & 7.618 & & \\
\cline { 2 - 7 } & Total & 2100.286 & 41 & & & \\
\hline
\end{tabular}

a. Predictors: (Constant), treatment pretest

b. Predictors: (Constant), treatment pretest, frequency

c. Dependent Variable: treatment posttest

$F$ value and its corresponding $p$ are seen in ANOVA (Table 11). With $p=0.000$, the regression is significant.

Table 12. Coefficients ${ }^{\mathrm{a}}$

\begin{tabular}{lrrrrrr}
\hline & \multicolumn{2}{c}{ Unstandardized Coefficients } & \multicolumn{2}{c}{ Standardized Coefficients } & & \\
\cline { 2 - 5 } Model & $\mathrm{B}$ & \multicolumn{2}{c}{ Std. Error } & Beta & \multicolumn{1}{c}{ Sig. } \\
\hline 2 (Constant) & 8.889 & 3.661 & & 2.428 & .020 \\
\hline treatment pretest & .820 & .055 & & 1.000 & 14.906 & .000 \\
\hline frequency & .188 & .019 & & .670 & 9.990 & .000 \\
\hline
\end{tabular}

a. Dependent Variable: treatment posttest

Table 12 shows the coefficients of the constant, pretest scores $(X 1)$, and use frequency of AEA system $(X 2)$, and their corresponding $\mathrm{p}$ is $0.02(<0.05), 0.000(<0.001)$, and $0.000(<0.001)$ respectively, resulting in the linear regression formula of students' writing improvement $(Y)$ related to the two variables above.

$$
Y=8.889+0.820 X 1+0.188 \times 2
$$

Formula (2) can be used to predict the improvement of students' proficiency in writing through current proficiency and use frequency of AEA system.

(1) Both of the two variables have positive effects on students' writing improvement;

(2) Effects of students' current proficiency in writing on their proficiency improvement: every 1 increase in students' current proficiency in writing (pretest scores) corresponds to 0.820 increase in their proficiency improvement without any other conditions changed.

(3) Effects of students' use frequency of ASA system on their proficiency improvement: every 1 increase in students' use frequency of ASA system corresponds to 0.188 increase in students' writing improvement without any other conditions changed.

Even though students' current proficiency in writing is the dominating factor of their proficiency improvement, their use frequency of ASA system can still affect as well, which proves "practice makes perfect". Therefore, every effort that students make is worthwhile.

\subsection{EFL Students' Perception on AEA System}

After the sixteen-week treatment period, the treatment group was asked to hand in their learning journals and interviews were conducted. From the information within, we can discover effects of using the online AEA system on EFL graduate students' writing in two aspects.

\subsubsection{The Online AEA System Improves EFL Graduate Students' Proficiency in Writing}

The online AEA system enforces instant feedback in the formative assessment, which increases the interaction of the writing process, thus stimulating students' interests in writing. Feedback is the most essential part of the 
formative assessment, and the instant feedback contributes the most to learning improvement (Black \& William, 1998).

Student A: "I like the grading system and the ranking system, from which I can know my writing proficiency."

Student B: "I think the grading system is just like that in Karaoke. It's full of fun to know the score at once."

When asked "what do you gain by using the AEA system", students' answers ranged from "improving my comprehensive language ability", to "discriminating words", "using advanced words", "enhancing fixed collocations", even to "turning simple sentences to compound sentences". Every time when they struggle to boost their scores, their English is improved unconsciously and simultaneously. It also proves Dickinson's (1995) notion that motivation can be enhanced through encouraging learners to exert personal control over their learning and to take responsibility for it.

\subsubsection{The Online AEA System Changes EFL Graduate Students’ Writing Process}

Teachers are no longer the only authority; instead, computer becomes the marker so that students can revise their essays to their extent until they hand in the final version to their human teacher. It enhances students' autonomy in writing.

Student C: "What I like most in this system is that it can stimulate me to improve my writing and with its help, I know how to revise my essay. That's amazing."

Student D: "Time flies when I revise my writing online."

Student E: "Writing becomes a kind of competition. I corrected one of my essays for almost twenty times just for satisfactory score, which is unbelievable if I hand it in to my teacher."

Student F: "I'm willing to write on my own, and I will never feel the force of writing assigned by my teacher."

\section{Conclusion}

The AEA system contributes greatly to improving EFL graduate students' writing, and enhancing their motivation and autonomy in learning English as long as they put enough efforts and time in using it, thus casting doubts on the criticism that students' motivation will be diminished if they know that no human will read their writing. Moreover, the linear regression model is constructed to predict the relation between how much students improve their writing and how much the effort students put in so as to enable students to be more confident in "practice makes perfect". The more time and energy they consume in practicing their writing, the higher efficiency they will have in their writing.

As educators, accordingly, we should creatively use the new technologies to provide learners with opportunities and environment that lie beyond the present scope of the classroom and enable them to step into a computer-assisted autonomous language learning community. At the same time, we should use the technology to stimulate their motivations and interests in autonomous learning in order to make the most of the language learning experience. Therefore, it's of practical significance to apply information technology to enhance EFL learner autonomy and their proficiency in writing.

\section{References}

Black, P., \& William, D. (1998). Assessment and classroom learning. Assessment in Education, 5(1), 7-74. http://dx.doi.org/10.1080/0969595980050102

Bruner, J. (1966). Toward a theory of instruction. Cambridge, MA: Harvard University Press.

Dickinson, L. (1995). Autonomy and motivation: a literature review. System, 23(2), 165-174. http://dx.doi.org/10.1016/0346-251X(95)00005-5

Dikli, S. (2006). An Overview of Automated Scoring of Essays. Journal of Technology, Learning, and Assessment, 5(1). Retrieved from http://ejournals.bc.edu/ojs/index.php/jtla/article/view/1640

Guey, C. C., Cheng Y. Y., \& Shibata S. (2010). A Triarchal Instruction Model: Integration of Principles from Behaviorism, Cognitivism, and Humanism Procedia - Social and Behavioral Sciences, 9, 105-118. http://dx.doi.org/10.1016/j.sbspro.2010.12.122

Holet, H. (1985). On Autonomy: Some Elementary Concepts. In Riley, P. (Ed.), Discourse and Learning. London: Longman.

Kakkonen, T., Myller, N., \& Sutinen, E. (2008). Comparison of Dimension Reduction Methods for Automated Essay Grading. Educational Technology \& Society, 11(3), 275-288. Retrieved from http://ifets.info/journals/11_3/19.pdf 
Liang, M. S., \& Wen, Q. F. (2007). A Critical Review and Implications of Some Automated Essay Scoring Systems. Computer-Assisted Foreign Language Education, 117(10), 18-24.

Little, D. (1991). Autonomy: Definitions, Issues and Problems. Dublin: Authentik.

Rudner, L. M., \& Liang, T. (2002). Automated Essay Scoring Using Bayes' Theorem. The Journal of Technology, Learning, and Assessment, 1(2). http://ejournals.bc.edu/ojs/index.php/jtla/article/view/1668

Sun, C. H. (2012). The Impact of Online Automated Writing Evaluation: A Case Study from Dalian. Chinese Journal of Applied Linguistics, 35(1), 63-79, 129.

Tang, J. L., \& Wu, Y. A. (2011). Using Automated Writing Evaluation in Classroom Assessment: A Critical Review. Foreign Language Teaching and Research, 43(2), 273-282, 321.

Tang, J. L., \& Wu, Y. A. (2012). Study on the Application of Automated Writing Assessment System in College EFL Teaching. Foreign Languages and Their Teaching, 256(4), 53-59.

Valenti, S., Neri, F., \& Cucchiarelli, A. (2003). An Overview of Current Research on Automated Essay Grading. Journal of Information Technology Education, (2), 19-330. Retrieved from http://jite.org/documents/Vol2/v2p319-330-30.pdf

Wang, J. Q., \& Wen, Q. F. (2010). Review and Implications of the Existing Automated Scoring Systems - from the Perspective of the Computer-assisted Scoring Model of Chinese EFL Learners' Translation. Foreign Language World, 136(1), 75-81, 91.

Weigle, S. C. (2002). Assessing Writing. Cambridge: Cambridge University Press.

\section{Copyrights}

Copyright for this article is retained by the author(s), with first publication rights granted to the journal.

This is an open-access article distributed under the terms and conditions of the Creative Commons Attribution license (http://creativecommons.org/licenses/by/3.0/). 